\title{
On the Alkylation of the 2,4,6-Triphenylthiopyran Anion
}

\author{
Jesper S. Kristensen and Henning Lund \\ Department of Organic Chemistry, University of Aarhus, DK-8000 Aarhus C, Denmark
}

Kristensen, J. S. and Lund, H., 1990. On the Alkylation of the 2,4,6-Triphenylthiopyran Anion. - Acta Chem. Scand. 44: 524-526.

Some years ago a report ${ }^{1}$ on the unusual reactivity of the $2 H$-thiopyran anion in alkylation with $t$-butyl bromide was published. It was found that the anion of $2 \mathrm{H}$-thiopyran, generated from $2 \mathrm{H}$-thiopyran and an excess of potassium amide in liquid ammonia, reacted with $t$-butyl bromide in a fast reaction to 2 - $t$-butyl- $2 H$-thiopyran in up to $54 \%$ yield. Even at $-65^{\circ} \mathrm{C}$ the $t$-butylation in liquid ammonia was complete within $2 \mathrm{~min}$. The unusual reactivity of the $2 \mathrm{H}$ thiopyran anion was tentatively ascribed to the high basicity of the anion.

At about the same time, the $t$-butylation of the electrogenerated anion of 4-methoxycarbonyl-1-methyl-1,4-dihydropyridine $\left(\mathbf{1}^{-}\right)$was described. ${ }^{2}$ It was suggested that the alkylation took place via an electron transfer (ET) from the anion to the alkyl halide, followed by a combination of the radicals, eqn. (1).

$\mathrm{A}^{-}+\mathrm{BX} \rightarrow\left[\mathrm{A}^{\cdot}+\mathrm{B}^{\cdot}+\mathrm{X}^{-}\right] \rightarrow \mathrm{AB}+\mathrm{X}^{-}$

Later kinetic $^{3}$ and stereochemical ${ }^{4}$ investigations suggested that in some aliphatic nucleophilic substitutions the transfer of an electron was the rate-determining step and that the alkyl radical was sufficiently long-lived to stereoisomerize before the coupling, but not long-lived enough to leave the solvent cage.<smiles></smiles>

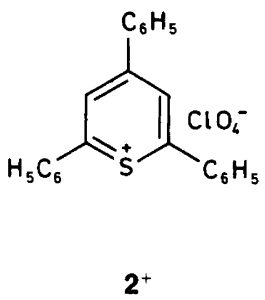

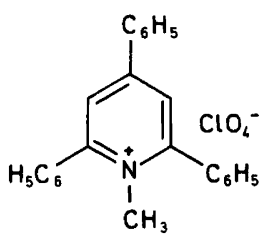

$3^{+}$
The similarities between the reactions of $t$-butyl bromide with $2 H$-thiopyran anion $\left(2^{-}\right)$and the dihydropyridine anion $\left(1^{-}\right)$suggested that the former also might involve an ET reaction. In order to gain information on that, the electrochemical reduction of 2,4,6-triphenylthiopyrylium perchlorate $\left(2^{+}\right)$and 1-methyl-2,4,6-triphenylpyridinium perchlorate $\left(3^{+}\right)$was investigated by cyclic voltammetry (CV), homogeneous kinetics using an ultramicroelectrode as an indicator electrode, and preparative reductions in the presence of benzyl chloride (5) and $t$-butyl bromide (6).

\section{Results and discussion}

Cyclic voltammetry of $2^{+}$in DMF/TBABF 4 showed two reversible reductions with $E_{\mathrm{p}}(1)=+0.233 \mathrm{~V}$ and $E_{\mathrm{p}}(2)=$ $-0.737 \mathrm{~V}$ vs. Ag/AgI, $0.1 \mathrm{M} \mathrm{I}^{-}$. Under similar conditions $3^{+}$also was reduced in two reversible steps, $E_{\mathrm{p}}(1)=$ $-0.538 \mathrm{~V}$ and $E_{\mathrm{p}}(2)=-0.983 \mathrm{~V}$. In both cases the reversible oxidation potential of the anion is thus known. The

Table 1. Rate constants for the reaction of $2^{-}, 3^{-}$and some anion radicals with benzyl chloride (5) and $t$-butyl bromide (6) in DMF/0.1 M TBABF $4,25^{\circ} \mathrm{C}$.

\begin{tabular}{|c|c|c|c|c|}
\hline$A$ & $B X$ & $-E_{A} N^{a}$ & $k / M^{-1} s^{-1}$ & $\log k$ \\
\hline 2-Methoxyazobenzene ${ }^{b}$ & 5 & 0.898 & 18.7 & 1.27 \\
\hline$p$-Diacetylbenzene ${ }^{b}$ & 5 & 1.006 & 56.0 & 1.75 \\
\hline Tetracene $^{b}$ & 5 & 1.097 & 356 & 2.56 \\
\hline Quinoxaline $^{b}$ & 5 & 1.200 & 826 & 2.92 \\
\hline Perylene $^{b}$ & 5 & 1.213 & 961 & 2.98 \\
\hline Benzophenone $b$ & 5 & 1.320 & 4694 & 3.67 \\
\hline 9,10-Diphenylanthracene ${ }^{b}$ & 5 & 1.404 & 40500 & 4.61 \\
\hline Anthracene $^{b}$ & 5 & 1.488 & 127000 & 5.10 \\
\hline $2^{-}$ & 5 & $0.737^{c}$ & 113 & 2.05 \\
\hline $3^{-}$ & 5 & $0.983^{c}$ & 408 & 2.61 \\
\hline Anthraquinone & 6 & 0.400 & $2.14 \times 10^{-4}$ & -3.67 \\
\hline p-Chloronitrobenzene & 6 & 0.555 & $4.27 \times 10^{-3}$ & -2.37 \\
\hline Azobenzene & 6 & 0.879 & $1.35 \times 10^{-1}$ & -0.87 \\
\hline p-Diacetylbenzene & 6 & 1.006 & $3.24 \times 10^{-1}$ & -0.49 \\
\hline 2 & 6 & $0.737^{c}$ & $6.46 \times 10^{-2}$ & -1.19 \\
\hline $3^{-}$ & 6 & $0.983^{c}$ & $2.88 \times 10^{-3}$ & -2.54 \\
\hline
\end{tabular}

${ }^{a}$ vs. Ag/Agl, $0.1 \mathrm{M} \mathrm{I}^{-} .{ }^{b}$ From Ref. 3. ${ }^{c}$ 2nd wave. 


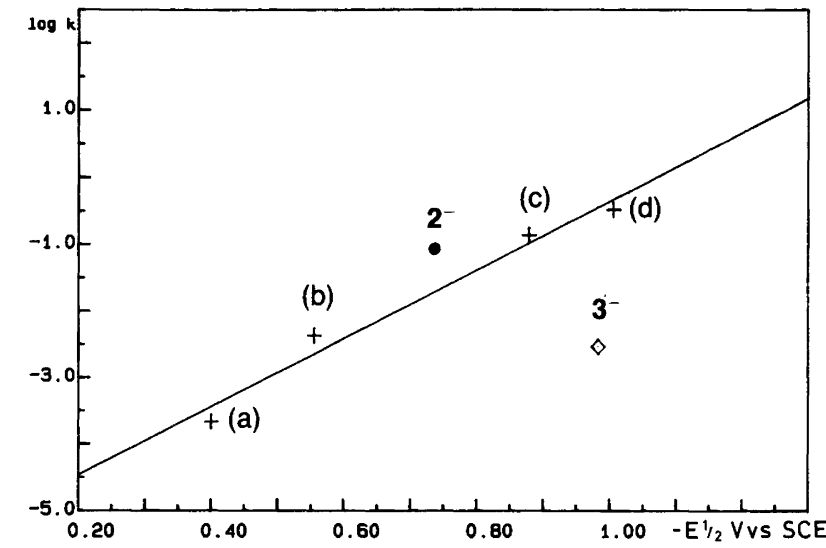

Fig. 1. Rate of electron transfer from some electrogenerated anion radicals, $2^{-}$, and $3^{-}$, to $t$-butyl bromide in $\mathrm{DMF}^{-} / \mathrm{TBAF}_{4}$ : (a) anthraquinone; (b) p-chloronitrobenzene; (c) azobenzene; (d) p-diacetylbenzene.

rate of electron transfer between some anion radicals of aromatic compounds and $t$-butyl bromide was investigated in homogeneous solution (DMF/TBABF ${ }_{4}$ ) using an ultramicroelectrode ${ }^{5}$ as the indicator electrode; the rate of the reaction between $2^{-}$and 6 was investigated in a similar way and the results given in Table 1 and shown in Fig. 1. Included in the Table are also the rate of the reaction between $2^{-}$and benzyl chloride and between $3^{-}$and $t$-butyl bromide and benzyl chloride.

As seen from Fig. 1, which depicts the rate constants of the ET reaction of some anion radicals and the rate of the substitution reaction of $2^{-}$and $3^{-}$with $t$-butyl bromide vs. the reversible oxidation potentials of the anions, the point of $2^{-}$is close to the best line through the points of the anion radicals. Based on the assumption that the rate-determining step of the reaction between aromatic anion radicals and $t$-butyl bromide is an outer-sphere electron transfer the results indicate that the rate-determining step in the coupling reaction between $2^{-}$and $\mathbf{6}$ is an electron transfer. This is independent of whether the correlation between $k$ and $E_{\mathrm{A}}^{\circ}$ is linear or quadratic, the latter required by the Marcus equation.

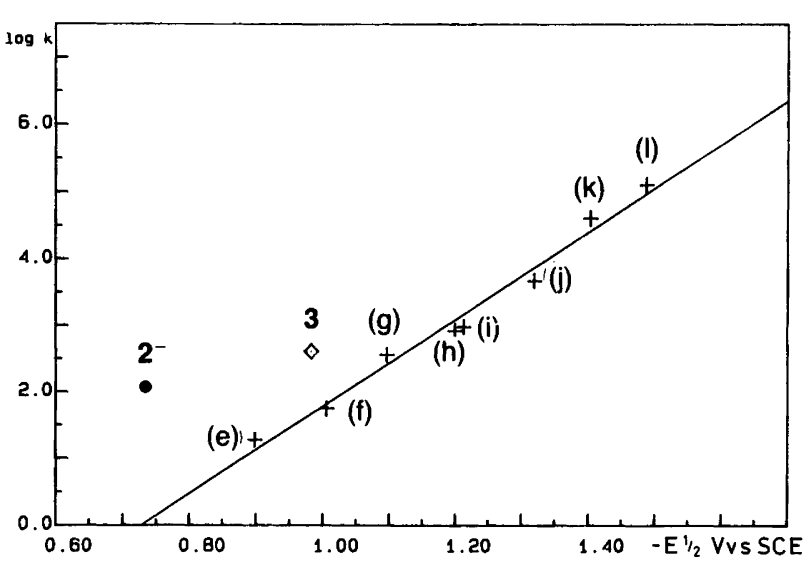

Fig. 2. Rate of electron transfer from some electrogenerated anion radicals, $2^{-}$, to benzyl chloride in $\mathrm{DMF} / \mathrm{TBABF}_{4}$ :

(e) 2-methoxyazobenzene; (f) p-diacetylbenzene; (g) tetracene; (h) quinoxaline; (i) perylene; (j) benzophenone; (k) 9,10diphenylanthracene; (I) anthracene.

The reaction of $3^{-}$with $t$-butyl bromide is slower than expected from the oxidation potential of the anion. Possibly the $N$-methyl group forces the 2- and 6-phenyl groups out of coplanarity with the central ring which might make the electron transfer slower due to a sterically inhibited approach of the reactant to the central ring; the ET would then occur at a greater distance from $3^{-}$than from $2^{-}$and thus be slower than expected.

In Fig. 2 the rate constants of some anion radicals and $\mathbf{2}^{-}$ and $3^{-}$with benzyl chloride (5) are shown. In the reaction of $1^{-}$with 5 the rate of $1^{-}$is about 100 times higher than that of an anion radical with the same oxidation potential, and a similar difference is found for $2^{-}$; on the basis of that, the rate of reaction of $3^{-}$with 5 is slower than expected as is the case of the reaction between $3^{-}$and 6 .

The preparative reduction of $2^{+}$at the potential of its second reduction wave in acetonitrile, in the presence of $t$-butyl iodide gave two products in about $50 \%$ yield $4 \mathrm{~A}$ and 4B in the ratio 1:3. The ${ }^{1} \mathrm{H}$ NMR and MS spectra of the compounds (see the Experimental) were in accordance with the assumption that the major product $4 B$ was<smiles></smiles><smiles>[X]C1(c2ccccc2)C=C(c2ccccc2)SC(c2ccccc2)=C1</smiles> 
2-t-butyl-2,4,6-triphenyl- $2 \mathrm{H}$-thiopyran and $\mathbf{4 A}$ was 4 - $t$ butyl-2,4,6-triphenyl-4H-thiopyran. On catalytic hydrogenation $\left(\mathrm{PtO}_{2} / \mathrm{C}\right)$ of the product mixture two moles of hydrogen per mole of substrate were absorbed.

Reduction of $2^{+}$under similar conditions in the presence of benzyl bromide gave 4-benzyl-2,4,6-triphenyl-4H-thiopyran, in about $50 \%$ isolated yield. No 2 -isomer was isolated, but its formation to some extent cannot be excluded.

Reduction of $3^{+}$in DMF in the presence of benzyl bromide or chloride gave 4-benzyl-1-methyl-2,4,6-triphenyl-1,4-dihydropyridine in about $20 \%$ isolated yield; no indication of a 2-isomer was apparent in the ${ }^{1} \mathrm{H}$ NMR spectrum of the crude product. In the presence of $t$-butyl bromide, 4- $t$-butyl-1-methyl-2,4,6-triphenyl-1,4-dihydropyridine was isolated in about $20 \%$ isolated yield. The products from $3^{+}$thus differ from those of $2^{+}$in that substitution takes place solely at C-4.

The similarities in the reactions of $2^{-}$and $2 \mathrm{H}$-thiopyran anion with $t$-butyl bromide suggest that the reaction of $2 \mathrm{H}$-thiopyran anion ${ }^{1}$ involves an electron transfer followed by coupling of the $t$-butyl radical with the thiopyranyl radical to the isolated product. The oxidation potential of the $2 \mathrm{H}$-thiopyran anion would be expected to be more negative than that of $2^{-}$and the ET step thus even faster. The reaction between $2 H$-thiopyran anion and $t$-butyl bromide would thus, if the ET step were rate-determining as it seems likely, be expected to be a fast reaction, as is in fact observed. ${ }^{1}$

\section{Experimental}

Reduction of $2^{+}$and $\mathrm{t}$-butyl iodide. $\mathbf{2}^{+}(300 \mathrm{mg})$ was reduced at $-0.9 \mathrm{~V}$ vs. $\mathrm{Ag} / \mathrm{AgI}$ (2nd wave) in acetonitrile containing $0.1 \mathrm{M} \mathrm{TBABF}_{4}$ in the presence of $t$-butyl iodide $(0.15 \mathrm{ml})$. When the reduction was complete, the catholyte was diluted with water and the products extracted with diethyl ether which was dried and evaporated. The residue (196 mg) was separated on a column of $\mathrm{Al}_{2} \mathrm{O}_{3}$ with $5 \%$ diethyl ether in light petroleum (b.p. $40-50^{\circ} \mathrm{C}$ ) as the eluent. The ${ }^{1} \mathrm{H}$ NMR spectrum of the major fraction indicated two compounds $4 \mathrm{~A}$ and $\mathbf{4 B}$ in the ratio $1: 3$. $\mathbf{4 A}$, 4-t-butyl-2,4,6-triphenyl-4H-thiopyran, ${ }^{1} \mathrm{H} \mathrm{NMR}\left(\mathrm{CDCl}_{3}\right)$ : $\delta 1.05(\mathrm{~s}, 9 \mathrm{H}), 6.61(\mathrm{~s}, 2 \mathrm{H}) .4 \mathrm{4B}, 2-t$-butyl-2,4,6-triphenyl-2H-thiopyran: ${ }^{1} \mathrm{H}$ NMR $\left(\mathrm{CDCl}_{3}\right): \delta 1.10(\mathrm{~s}, 9 \mathrm{H})$, $6.41(\mathrm{~s}, 1 \mathrm{H}), 6.65(\mathrm{~s}, 1 \mathrm{H})$. For both: 7.05-7.75 (m, $15 \mathrm{H})$. MS: $m / z(\%) 326(52), 325(100), 249(20), 247$ (14), 215 (10), 121 (7), 91 (7), 57 (39), 43 (31), 41 (12). The mixture of $4 \mathrm{~A}$ and $4 \mathrm{~B}$ was hydrogenated over $\mathrm{PtO}_{2} / \mathrm{C} ; 2 \mathrm{~mol} \mathrm{H}_{2}$ per mol substrate was absorbed. ${ }^{1} \mathrm{H}$ NMR of the hydrogenated mixture $\left(\mathrm{CDCl}_{3}\right): \delta 1.03(\mathrm{~s})$ and $1.05(\mathrm{~s})($ total $9 \mathrm{H}), 1.75$ $2.00(\mathrm{~m}, 2 \mathrm{H}), 2.20-2.50(\mathrm{~m}, 2 \mathrm{H}), 2.80-3.00(\mathrm{~m}, 1 \mathrm{H})$, 3.35-3.55 (m, $1 \mathrm{H}), 6.90-7.70(\mathrm{~m}, 15 \mathrm{H})$.
Reduction of $2^{+}$and benzyl bromide. $2^{+}(200 \mathrm{mg})$ was reduced as described above in the presence of benzyl bromide $(0.1 \mathrm{ml})$. 4-Benzyl-2,4,6-triphenyl-4H-thiopyran was isolated as above in about $50 \%$ yield. ${ }^{1} \mathrm{H}$ NMR $\left(\mathrm{CDCl}_{3}\right): \delta 3.35(\mathrm{~s}, 2 \mathrm{H}), 5.95(\mathrm{~s}, 2 \mathrm{H}), 6.8-7.7(\mathrm{~m}, 20 \mathrm{H})$. MS: $m / z(\%) 416(23), 325$ (32), 205 (22), 149 (22), 142 (44), 122 (52), 105 (100), 91 (40), 77 (77). As the signals from the two protons in the thiopyran ring gave only one signal, the compound was assumed to be substituted with benzyl in the 4-position.

Reduction of $3^{+}$and benzyl bromide. $3^{+}(300 \mathrm{mg})$ was reduced at $-1.05 \mathrm{~V}$ vs. $\mathrm{Ag} / \mathrm{AgI}$ (2nd wave) in DMF/0.1 M $\mathrm{TBABF}_{4}$ in the presence of $1.0 \mathrm{ml}$ of benzyl chloride. The product was isolated as described above. ${ }^{1} \mathrm{H}$ NMR of the product, 4-benzyl-1-methyl-2,4,6-triphenyl-1,4-dihydropyridine, $\left(\mathrm{CDCl}_{3}\right): \delta 1.95(\mathrm{~s}, 3 \mathrm{H}), 3.25(\mathrm{~s}, 2 \mathrm{H}), 5.05$ $(\mathrm{s}, 2 \mathrm{H}), 7.1-7.7(\mathrm{~m}, 20 \mathrm{H}) .{ }^{13} \mathrm{C}$ NMR $\left(\mathrm{CDCl}_{3}\right): \delta 37.97$ $\left(\mathrm{CH}_{3}\right), 46.00(\mathrm{C}), 49.47\left(\mathrm{CH}_{2}\right), 111.59(\mathrm{CH}), 126.29(\mathrm{CH})$, $126.63(\mathrm{CH}), 127.53(\mathrm{CH}), 127.57(\mathrm{CH}), 128.17(\mathrm{CH})$, $128.36(\mathrm{CH}), 128.79(\mathrm{CH}), 132.11(\mathrm{CH}), 138.84(\mathrm{C})$, 139.50 (C), 144.79 (C), 151.77 (C). MS: $m / z$ (\%) 412 (7), 323 (35), 322 (100), 307 (41), 230 (12), 202 (5), 137 (11), 111 (13), 97 (16), 91 (15), 71 (14), 69 (39), 57 (20), 28 (32).

Reduction of $3^{+}$and t-butyl bromide. $3^{+}(300 \mathrm{mg})$ was reduced in $\mathrm{DMF} / 0.1 \mathrm{M} \mathrm{TBABF}_{4}$ in presence of $1.0 \mathrm{ml}$ $t$-butyl bromide. The product was recrystallized from diethyl ether/hexane. ${ }^{1} \mathrm{H}$ NMR of the product, 4-t-butyl-1methyl-2,4,6-triphenyl-1,4-dihydropyridine, $\left(\mathrm{CDCl}_{3}\right): \delta$ $0.90(\mathrm{~s}, 9 \mathrm{H}), 2.42(\mathrm{~s}, 3 \mathrm{H}), 5.55(\mathrm{~s}, 2 \mathrm{H}), 7.1-7.6(\mathrm{~m}$, 15 H). MS: $m / z$ (\%) 379 (3), 322 (100), 307 (25), $306(21)$, 230 (9), 201 (9), 77 (8). M.p. $144-145^{\circ} \mathrm{C}$.

\section{References}

1. Gräfing, R., Verkruijsse, H. D. and Brandsma, L. J. Chem. Soc., Chem. Commun. (1978) 596.

2. Lund, H. and Kristensen, L. H. Acta Chem. Scand., Ser. B 33 (1979) 495.

3. Lund, T. and Lund, H. Acta Chem. Scand., Ser. B 40 (1986) $470 ; 41$ (1987) 93.

4. Daasbjerg, K., Lund, T. and Lund, H. Tetrahedron Lett. 30 (1989) 493.

5. Pedersen, S. U. and Daasbjerg, K. Acta Chem. Scand. 43 (1989) 301.

Received December 4, 1989. 